\title{
The interactions between cysteamine, cystine and cumulus cells increase the intracellular glutathione level and developmental capacity of goat cumulus-denuded oocytes
}

\author{
Ping Zhou, Yan-Guang Wu, Qing Li, Guo-Cheng Lan, Gang Wang, Da Gao and Jing-He Tan \\ Laboratory for Animal Reproduction and Embryology, College of Animal Science and Veterinary Medicine, Shandong \\ Agricultural University, Taian City 271018, Shandong Province, People's Republic of China
}

Correspondence should be addressed to J-H Tan; Email: tanjh@sdau.edu.cn

\begin{abstract}
To improve in vitro maturation (IVM) of denuded oocytes (DOs), we observed the interactive effects of cysteamine, cystine and cumulus cells on the glutathione (L- $\gamma$-glutamyl-L-cysteinyl-glycine; GSH) level and developmental capacity of goat IVM oocytes. Cysteamine supplementation increased the GSH level and blastocyst rates of both cumulus-oocyte complexes (COCs) and DOs, while the addition of cystine increased the GSH level and blastulation only in the presence of cumulus cells (COCs or DOs co-cultured on a cumulus cell monolayer). Simultaneous supplementation of cysteamine and cystine increased the GSH content and blastulation of co-cultured DOs to a level similar to that of COCs matured without thiol supplementation. Co-culture without thiol supplementation improved DOs' GSH synthesis but not blastulation. The results suggest that DOs cannot utilize cystine for GSH synthesis unless exogenous cysteamine is supplied by either cumulus cells or supplementation. Thus, while the addition of cystine alone is enough to improve IVM of COCs, improvement of DOs requires supplementation of both cystine and cysteamine. Synergic actions between cysteamine, cystine and cumulus cells restore the GSH level and developmental capacity of goat DOs.
\end{abstract}

Reproduction (2008) 135 605-611

\section{Introduction}

Removal of cumulus cells before in vitro maturation (IVM) was detrimental to oocyte maturation, and co-culture with cumulus-oocyte complexes (COCs) or cumulus cells restored partially the developmental potential of cumulus-denuded oocytes (DOs). Therefore, cumulus cells are considered to play an important role in oocyte maturation by regulating meiotic progression and by supporting cytoplasmic maturation (Tanghe et al. 2002). However, the removal of cumulus cells from oocytes or zygotes at various stages of development is inevitable for some embryo manipulation techniques. Therefore, an efficient IVM system for DOs will provide a technical approach to such procedures as germinal vesicle (GV) transfer, somatic cell haploidization and oocyte cryopreservation at the GV stage. In addition, the mechanisms by which cumulus cells improve oocyte maturation are poorly understood.

Glutathione (L- $\gamma$-glutamyl-L-cysteinyl-glycine; GSH) is well known to play an important role in protecting cells against the destructive effects of reactive oxygen species, and to regulate protein and DNA synthesis by altering redox status (Meister 1983). In reproduction, GSH participates in sperm decondensation and male pronucleus formation in hamsters (Perreault et al. 1988), pigs (Yoshida et al. 1993) and cows (Sutovsky \& Schatten 1997). Moreover, cytoplasmic GSH is also defined as one of the indices of cytoplasmic maturation (Funahashi et al. 1994, de Matos et al. 1997, Abeydeera et al. 1998, Furnus et al. 1998, de Matos \& Furnus 2000). Synthesis of GSH is highly dependent on the availability of cysteine in the medium (Meister \& Tate 1976, Chance et al. 1979). It is thought that GSH synthesis under in vitro conditions may be impaired because of a deficiency of cysteine in the culture medium $(0.6 \mu \mathrm{M}$ in TCM-199) and its high instability and easy auto-oxidation to cystine (Bannai 1984, Sagara et al. 1993). In somatic cells, cysteamine can reduce cystine to cysteine, promoting cysteine uptake and hence enhancing GSH synthesis (Issels et al. 1988). The addition of cysteamine to the culture medium improved oocyte maturation and development by increasing the GSH content of COCs (de Matos et al. 1995, 2002, 2003, Abeydeera et al. 1998, Gasparrini et al. 2000, Rodriguez et al. 2003, Kobayashi et al. 2006). However, whether the cystine contained in TCM-199 $(83.2 \mu \mathrm{M})$ is sufficient for oocyte IVM of different species is unknown. While enrichment of maturation medium with cystine increased both GSH contents and embryonic development in the cow (de Matos et al. 1997, de Matos \& Furnus 2000) 
and buffalo (Gasparrini et al. 2006), it increased only GSH synthesis of goat oocytes (Rodriguez et al. 2003).

The GSH content of an oocyte is highly correlated with the presence of cumulus cells (Sawai et al. 1997). Reports indicate a lower GSH content of DOs after IVM than of COCs (de Matos et al. 1997, Luciano et al. 2005, Maedomari et al. 2007). However, while co-culture with intact COCs induced a significant increase in the GSH content of bovine DOs (Luciano et al. 2005), co-culture with a monolayer of cumulus cells had no beneficial effect on the GSH synthesis of porcine (Maedomari et al. 2007) and mouse (data to be published) DOs. Besides, the addition of cysteamine to culture medium increased the GSH content and formation of male pronuclei but had no effect on the nuclear maturation of porcine DOs (Yamauchi \& Nagai 1999). The addition of cysteamine to culture medium also increased intracellular GSH of bovine DOs (de Matos et al. 1997). In addition, de Matos et al. (1997) found that supplementation of TCM-199 with cystine had no effect on the GSH synthesis of bovine DOs cultured alone but increased GSH levels after IVM of bovine DOs in the presence of cumulus cell monolayer. However, the effect of addition of cysteamine or cystine to maturation medium on embryonic development of DOs has not been reported.

In summary, the above review indicates that while cysteamine increases the GSH content of oocytes matured as DOs, its effect on the developmental competence of these oocytes is uncertain. Results on the effect of cystine supplementation on IVM of COCs are in conflict, and its effect on DOs needs investigation. The exact role of gap junctional communication between the oocyte and cumulus cells in GSH transport or synthesis is unclear. In addition, since the effect of GSH on oocyte developmental competence was usually evaluated after in vitro fertilization, whether the beneficial effect was due to an increased male pronuclear formation or an improved subsequent development is unknown, although de Matos et al. (1995) observed that while a higher GSH level in mature bovine oocytes was correlated with increased blastocyst formation, it had no effect on cleavage rates. The best way to answer this question is to observe development after parthenogenetic activation. In this paper, we have studied the interactive effects of cysteamine, cystine and cumulus cells on the GSH synthesis and cytoplasmic maturation of goat oocytes, and have reported that IVM of DOs could be improved by manipulating the interactions between these factors.

\section{Results}

\section{The optimal concentrations of cysteamine and cystine for the improvement of GSH synthesis and developmental competence of goat oocytes}

When goat COCs were cultured in TCM-199 supplemented with different concentrations of cysteamine or cystine, the content of intracellular GSH increased with increasing cysteamine or cystine concentrations (Table 1). However, the highest rate of blastocyst formation was achieved only at $100-\mu \mathrm{M}$ cysteamine or 200- $\mu \mathrm{M}$ cystine, with blastocyst rates decreasing at higher concentrations. A similar pattern of changes was observed in the average cell number per blastocyst among cysteamine or cystine concentrations, although differences between treatments were not always statistically significant. Rates of oocyte maturation did not differ between concentrations of cysteamine or cystine.

\section{Effects of cysteamine and cystine alone or in combination on GSH synthesis and developmental competence of goat COCs}

The addition of either $100-\mu \mathrm{M}$ cysteamine or $200-\mu \mathrm{M}$ cystine to TCM-199 improved both GSH synthesis and blastulation of goat COCs. When both cysteamine and cystine were added, the rate of blastocyst formation was further increased (Table 2). The same tendency of changes was observed in the average cell number per

Table 1 Maturation, blastocysts formation, and oocyte intracellular glutathione (GSH) concentration after culture of cumulus-oocyte complexes (COCs) in TCM-199 supplemented with different concentrations of cysteamine or cystine.

\begin{tabular}{|c|c|c|c|c|c|c|c|}
\hline $\begin{array}{l}\text { Cysteamine } \\
(\mu \mathrm{M})\end{array}$ & $\begin{array}{l}\text { Cystine } \\
(\mu M)\end{array}$ & $\begin{array}{l}\text { Oocytes } \\
\text { cultured }\end{array}$ & \% MII oocytes & $\begin{array}{l}\text { Embryos } \\
\text { cultured }\end{array}$ & $\%$ Blastocysts & Cell no./blastocyst & GSH (pmol/oocyte) \\
\hline 0 & & 138 & $83.3 \pm 2.3^{a}$ & 103 & $10.7 \pm 1.0^{\mathrm{a}}$ & $80.7 \pm 3.6^{\mathrm{a}}$ & $2.26 \pm 0.21^{\mathrm{a}}$ \\
\hline 50 & & 136 & $83.4 \pm 1.9^{a}$ & 103 & $18.4 \pm 1.0^{b}$ & $110.7 \pm 14.2^{a, b}$ & $3.51 \pm 0.06^{b}$ \\
\hline 100 & & 156 & $83.6 \pm 2.0^{\mathrm{a}}$ & 104 & $25.9 \pm 1.7^{\mathrm{c}}$ & $128.1 \pm 17.1^{\mathrm{b}}$ & $4.38 \pm 0.27^{\mathrm{c}}$ \\
\hline 200 & & 172 & $85.0 \pm 2.2^{\mathrm{a}}$ & 107 & $21.0 \pm 1.3^{b}$ & $104.1 \pm 11.3^{a, b}$ & $5.08 \pm 0.33^{d}$ \\
\hline \multirow[t]{5}{*}{500} & & 181 & $82.0 \pm 3.7^{\mathrm{a}}$ & 114 & $10.9 \pm 1.4^{\mathrm{a}}$ & $79.2 \pm 3.6^{\mathrm{a}}$ & $5.98 \pm 0.24^{\mathrm{e}}$ \\
\hline & 0 & 159 & $81.2 \pm 5.7^{\mathrm{a}}$ & 99 & $14.1 \pm 2.1^{\mathrm{a}}$ & $93.4 \pm 11.7^{\mathrm{a}}$ & $3.04 \pm 0.23^{\mathrm{a}}$ \\
\hline & 100 & 131 & $80.7 \pm 2.5^{\mathrm{a}}$ & 98 & $10.2 \pm 0.5^{\mathrm{a}}$ & $93.1 \pm 12.5^{a}$ & $3.67 \pm 0.26^{b}$ \\
\hline & 200 & 156 & $81.7 \pm 4.2^{\mathrm{a}}$ & 101 & $31.4 \pm 1.8^{\mathrm{C}}$ & $136.7 \pm 16.3^{b}$ & $4.24 \pm 0.05^{\mathrm{c}}$ \\
\hline & 500 & 152 & $79.6 \pm 1.7^{a}$ & 100 & $19.7 \pm 2.5^{b}$ & $111.3 \pm 15.4^{\mathrm{a}, \mathrm{b}}$ & $4.74 \pm 0.13^{d}$ \\
\hline
\end{tabular}

\footnotetext{
${ }^{a-e}$ Values without a common letter in their superscripts in the same column differ $(P<0.05)$ within the cysteamine or cystine experiment. Each treatment was repeated six times and 20-30 and 15-20 oocytes were observed for maturation and embryo development, respectively, per replicate per treatment. Each sample for assay of the intracellular GSH level consisted of 30 oocytes and three samples from different experimental days were assayed for each treatment.
} 
Table 2 Maturation, blastocyst formation, and oocyte intracellular glutathione (GSH) concentration after culture of cumulus-oocyte complexes (COCs) in TCM-199 supplemented with cysteamine, cystine, or both.

\begin{tabular}{|c|c|c|c|c|c|c|c|}
\hline $\begin{array}{l}\text { Cysteamine } \\
(100 \mu \mathrm{M})\end{array}$ & $\begin{array}{l}\text { Cystine } \\
(200 \mu \mathrm{M})\end{array}$ & $\begin{array}{l}\text { Oocytes } \\
\text { cultured }\end{array}$ & $\%$ MII oocytes & $\begin{array}{l}\text { Embryos } \\
\text { cultured }\end{array}$ & $\%$ Blastocysts & Cell no./blastocyst & GSH (pmol/oocyte) \\
\hline- & - & 124 & $84.7 \pm 2.3^{\mathrm{a}}$ & 106 & $13.0 \pm 0.9^{\mathrm{a}}$ & $86.3 \pm 8.4^{\mathrm{a}}$ & $3.16 \pm 0.28^{\mathrm{a}}$ \\
\hline+ & - & 153 & $84.5+1.6^{a}$ & 104 & $24.2 \pm 2.0^{b}$ & $117.6+16.0^{a, b}$ & $4.61+0.07^{b}$ \\
\hline- & + & 156 & $82.5 \pm 1.5^{\mathrm{a}}$ & 97 & $27.1 \pm 1.6^{\mathrm{b}}$ & $125.2 \pm 15.6^{a, b}$ & $4.25 \pm 0.05^{\mathrm{b}}$ \\
\hline+ & + & 139 & $84.0 \pm 1.1^{\mathrm{a}}$ & 113 & $34.2 \pm 2.8^{\mathrm{C}}$ & $143.2 \pm 16.8^{\mathrm{b}}$ & $4.67 \pm 0.14^{b}$ \\
\hline
\end{tabular}

${ }^{\mathrm{a}, \mathrm{b}}$ Values without a common letter in their superscripts in the same column differ $(P<0.05)$. Each treatment was repeated six times and $20-30$ and 15-20 oocytes were observed for maturation and embryo development, respectively, per replicate per treatment. Each sample for assay of the intracellular GSH level consisted of 30 oocytes and three samples from different experimental days were assayed for each treatment.

blastocyst, although differences were not always statistically significant between treatments.

\section{Effects of cysteamine and cystine alone or in combination on GSH synthesis and developmental competence of goat cumulus-DOs}

The addition of $100-\mu \mathrm{M}$ cysteamine to TCM-199 improved GSH synthesis and blastulation as well as nuclear maturation of DOs (Table 3). The addition of $200-\mu \mathrm{M}$ cystine, however, did not have any beneficial effect on the DOs. When cysteamine and cystine were added together, GSH content and rate of blastocysts further increased $(P<0.05)$ relative to those obtained when cysteamine was added alone. The average cell number of blastocysts derived from DOs matured in the presence of cysteamine alone was lower than that of blastocysts from DOs matured in the presence of both cysteamine and cystine, although the difference was not statistically significant.

\section{Interactive effects of cysteamine, cystine and cumulus cells on GSH synthesis and developmental competence of goat DOs}

In the presence of neither cysteamine nor cystine, co-culture with cumulus monolayer increased nuclear maturation and GSH synthesis, but not blastulation of DOs (Table 4). Co-cultured with cumulus cell monolayer, the addition of either cysteamine or cystine improved both GSH synthesis and blastulation of DOs.
When cysteamine and cystine were added together, both the GSH level and the rate of blastocysts of the co-cultured DOs increased further to the same level as that of COCs cultured with no thiol supplementation (Table 2). The average cell number per blastocyst was significantly higher when both cysteamine and cystine were added together than when either one was added alone.

\section{Discussion}

The present results suggest that goat DOs cannot utilize cystine for GSH synthesis, unless in the presence of either supplemented cysteamine or cumulus cells. In the cow, an increase in GSH level stimulated by cystine was observed only in the presence of cumulus cells, either in COCs or in DOs matured on a co-culture monolayer (de Matos et al. 1997). However, embryonic development was not observed in that study. Takahashi et al. (1995) showed that bovine embryos can hardly utilize cystine for GSH synthesis, but in the presence of a cumulus-granulosa cell co-culture, they can utilize components derived from cystine metabolism secreted to the culture medium by the cell monolayer. Cysteine is an external substrate required for GSH synthesis in maturing bovine oocytes (de Matos et al. 1996). However, the concentration of cysteine in TCM-199 is very low $(0.6 \mu \mathrm{M})$, and outside the cell, essentially no cysteine will be present in TCM-199 due to autoxidation to cystine (Bannai 1984, Sagara et al. 1993). Therefore, it is possible that this cystine is converted into cysteine by

Table 3 Maturation, blastocyst formation, and oocyte intracellular glutathione (GSH) concentration after culture of denuded oocytes (DOs) in TCM199 supplemented with cysteamine, cystine, or both.

\begin{tabular}{lccccccc}
\hline $\begin{array}{l}\text { Cysteamine } \\
(100 \mu \mathrm{M})\end{array}$ & $\begin{array}{c}\text { Cystine } \\
(200 \mu \mathrm{M})\end{array}$ & $\begin{array}{c}\text { Oocytes } \\
\text { cultured }\end{array}$ & \% MII oocytes & $\begin{array}{c}\text { Embryos } \\
\text { cultured }\end{array}$ & \% Blastocysts & Cell no./blastocyst & GSH (pmol/oocyte) \\
\hline- & - & 158 & $59.8 \pm 1.8^{\mathrm{a}}$ & 92 & $0.0 \pm 0.0^{\mathrm{a}}$ & - & $1.43 \pm 0.21^{\mathrm{a}}$ \\
+ & - & 150 & $80.4 \pm 1.9^{\mathrm{b}}$ & 104 & $5.0 \pm 1.8^{\mathrm{b}}$ & $71.3 \pm 1.9^{\mathrm{a}}$ & $2.50 \pm 0.25^{\mathrm{b}}$ \\
- & + & 142 & $62.6 \pm 1.8^{\mathrm{a}}$ & 103 & $0.0 \pm 0.0^{\mathrm{a}}$ & - & $1.60 \pm 0.10^{\mathrm{a}}$ \\
+ & + & 147 & $80.8 \pm 1.1^{\mathrm{b}}$ & 102 & $9.6 \pm 1.5^{\mathrm{c}}$ & $103.2 \pm 17.5^{\mathrm{a}}$ & $3.10 \pm 0.16^{\mathrm{c}}$ \\
\hline
\end{tabular}

${ }^{\mathrm{a}-\mathrm{c}}$ Values without a common letter in their superscripts in the same column differ $(P<0.05)$. Each treatment was repeated six times and $20-30$ and 15-20 oocytes were observed for maturation and embryo development, respectively, per replicate per treatment. Each sample for assay of the intracellular GSH level consisted of 30 oocytes and three samples from different experimental days were assayed for each treatment. 
Table 4 Maturation, blastocyst formation, and oocyte intracellular glutathione (GSH) concentration after culture of denuded oocytes (DOs) in the presence of cumulus cell monolayer in TCM-199 supplemented with cysteamine, cystine, or both.

\begin{tabular}{lccccccc}
\hline $\begin{array}{l}\text { Cysteamine } \\
(100 \mu \mathrm{M})\end{array}$ & $\begin{array}{c}\text { Cystine } \\
(200 \mu \mathrm{M})\end{array}$ & $\begin{array}{c}\text { Oocytes } \\
\text { cultured }\end{array}$ & $\begin{array}{c}\text { \% MII } \\
\text { oocytes }\end{array}$ & $\begin{array}{c}\text { Embryos } \\
\text { cultured }\end{array}$ & \% Blastocysts & Cell no./blastocyst & GSH (pmol/oocyte) \\
\hline- & - & $158^{*}$ & $59.8 \pm 1.8^{\mathrm{a}}$ & 105 & $0.0 \pm 0.0^{\mathrm{a}}$ & - & $1.52 \pm 0.17^{\mathrm{a}}$ \\
- & - & 155 & $83.0 \pm 1.2^{\mathrm{b}}$ & 103 & $1.0 \pm 1.0^{\mathrm{a}}$ & - & $2.65 \pm 0.12^{\mathrm{b}}$ \\
+ & - & 159 & $84.8 \pm 1.5^{\mathrm{b}}$ & 112 & $8.4 \pm 1.4^{\mathrm{b}}$ & $76.6 \pm 10.6^{\mathrm{a}}$ & $3.27 \pm 0.31^{\mathrm{c}}$ \\
- & + & 153 & $81.6 \pm 1.4^{\mathrm{b}}$ & 94 & $8.7 \pm 21^{\mathrm{b}}$ & $72.1 \pm 7.3^{\mathrm{a}}$ & $2.53 \pm 0.08^{\mathrm{b}}$ \\
+ & + & 163 & $84.7 \pm 1.2^{\mathrm{b}}$ & 104 & $14.3 \pm 0.5^{\mathrm{c}}$ & $115.1 \pm 15.9^{\mathrm{b}}$ & $3.36 \pm 0.22^{\mathrm{c}}$ \\
\hline
\end{tabular}

${ }^{a-c}$ Values without a common letter in their superscripts in the same column differ $(P<0.05)$. Each treatment was repeated six times and $20-30$ and 15-20 oocytes were observed for maturation and embryo development, respectively, per replicate per treatment. Each sample for the assay of the intracellular GSH level consisted of 30 oocytes and three samples from different experimental days were assayed for each treatment.

*DOs were cultured without cumulus cell monolayer.

cumulus cells and then incorporated into GSH synthesis during IVM (Yoshida et al. 1993, Takahashi et al. 1995). Under physiological conditions, only $10-20 \%$ of the total free cystine is present as the reduced form (Meier \& Issels 1995).

In this study, cysteamine improved GSH synthesis and blastulation of DOs when added alone but increased GSH synthesis and the blastocyst formation further in the presence of either cumulus cell monolayer or cystine supplementation. The addition of cysteamine alone to IVM medium also increased GSH levels of bovine (de Matos et al. 1997) and porcine DOs (Yamauchi \& Nagai 1999) in the absence of cumulus cells, but the effect on embryo development was not reported. To our knowledge, for the first time we have reported the beneficial effect of simultaneous addition of cystine and cysteamine on the GSH synthesis and embryo development of DOs. In somatic cells, cysteamine can reduce cystine to cysteine, promoting cysteine uptake and hence enhancing GSH synthesis (Issels et al. 1988, Meier \& Issels 1995). While this helps to explain the mechanism by which cysteamine promotes the utilization of cystine, the synergic effect of the supplemented cystine and cysteamine on the non-co-cultured DOs in this study would suggest a deficiency of cystine in TCM-199. Then, how can one explain the synergic effect between cysteamine and the cumulus cells under the same concentration of cystine? According to the Michaelis-Menten equation (Michaelis \& Menten 1913), at a constant enzyme concentration, the turnover velocity $(v)$ of an enzyme increases as a function of the substrate concentration. Therefore, our explanation is that when either cysteamine or cumulus cells are involved, more substrates (cystine) are needed to produce enough cysteine for GSH synthesis and for the procurement of the ability to form blastocysts. When both cysteamine and cumulus cells are involved, however, more cysteine would be reduced from less cystine. The fact that when cysteamine and cystine were added together, both the rate of blastocysts and the GSH content of the co-cultured DOs increased to the same level as that of COCs cultured with no thiol supplementation further supports our hypothesis.
The removal of cumulus cells before IVM impaired both the developmental capacity (Schroeder \& Eppig 1984, Chian et al. 1994, Wongsrikeao et al. 2005) and the GSH synthesis (de Matos et al. 1997, Luciano et al. 2005, Maedomari et al. 2007) of oocytes. Many efforts have been made to improve the developmental potential of oocytes after cumulus denudation. However, co-culture with COCs or cumulus cells could only partially restore the developmental potential of DOs (Zhang et al. 1995, Hashimoto et al. 1998, Luciano et al. 2005, Ge et al. 2007), and whether co-culture would improve GSH synthesis of DOs is inconclusive (Luciano et al. 2005, Maedomari et al. 2007). The irreparability for the detrimental effect of cumulus removal has been attributed to the disruption of the gap junctions between cumulus cells and the oocyte, because co-culture with the cumulus cell monolayer completely restored the competence of corona-enclosed DOs (Hashimoto et al. 1998, Ge et al. 2008). However, this study demonstrated that in the presence of a cumulus cell monolayer, simultaneous addition of cysteamine and cystine to the culture medium increased the GSH content and the capacity to blastulate in DOs to the same level as in COCs matured under routine culture conditions. This suggests that it is possible to restore completely the developmental potential of DOs by regulating the IVM conditions, and will contribute to our understanding of the mechanisms by which cumulus cells promote oocyte maturation and to the establishment of an efficient DO IVM system.

Our results indicate that both cysteamine and cystine improve the GSH synthesis and developmental competence of goat COCs in a concentration-dependent manner. However, although the content of intracellular $\mathrm{GSH}$ increased with increasing concentrations of cysteamine or cystine up to $500-\mu \mathrm{M}$, the highest rate of blastocyst formation was achieved only at $100-\mu \mathrm{M}$ cysteamine or $200-\mu \mathrm{M}$ cystine, and blastocyst rates decreased at higher concentrations of the thiol compounds. Yamauchi \& Nagai (1999) also noticed that the addition of cysteamine in the culture medium at a concentration of $500 \mu \mathrm{M}$ resulted in the degeneration of porcine DOs, and none of them matured to 
metaphase II. However, they did not measure the GSH content of the DOs cultured under the same condition. To explain the decreased developmental capacity of oocytes matured under a high concentration of cysteamine or cystine, we speculate that too high a level of intracellular GSH would upset the redox homeostasis that is essential for normal functions such as gene expression of the cell (Arrigo 1999). Besides, in this study, co-culture without thiol supplementation increased only the GSH level but did not improve blastocyst formation of DOs. Furthermore, the mouse DOs showed impaired development while having a similar level of GSH as COCs after IVM (Ge et al. 2008). Therefore, it is suggested that the competence for embryonic development is not necessarily correlated with the intracellular GSH level of oocytes following IVM.

In conclusion, we have studied the interactive effects between cysteamine, cystine, and cumulus cells on the GSH synthesis and developmental competence of goat oocytes. The results suggest that DOs cannot utilize cystine for GSH synthesis unless exogenous cysteamine is supplied by either cumulus cells or supplementation. Therefore, while addition of cystine alone is enough to improve the IVM of COCs, improvement of DOs requires the supplementation of both cystine and cysteamine. Synergic actions between cysteamine, cystine, and cumulus cells restore the GSH level and developmental capacity of goat DOs. The data will contribute to our understanding of the mechanisms by which cumulus cells promote oocyte maturation and to the establishment of an efficient DO IVM system.

\section{Materials and Methods}

Unless otherwise indicated, all chemicals and drugs were purchased from Sigma Chemical Co.

\section{Recovery of oocytes}

Caprine ovaries were obtained from a local abattoir, and transported within $3 \mathrm{~h}$ to the laboratory in sterilized saline containing $100 \mathrm{IU} / \mathrm{ml}$ penicillin and $0.05 \mathrm{mg} / \mathrm{ml}$ streptomycin maintained at $30-35^{\circ} \mathrm{C}$. Collection and culture of oocytes were as described previously (Lan et al. 2006). Oocyte aspiration and selection were performed in Dulbecco's PBS (D-PBS), supplemented with $0.1 \%$ of polyvinyl alcohol. The COCs were aspirated with a syringe from antral follicles 2-5 $\mathrm{mm}$ in diameter and were examined under a stereomicroscope. Only COCs with more than three complete layers of cumulus cells and a finely granulated homogeneous ooplasm were used. The DOs were obtained by mechanically removing cells from COCs with a small-bore pipette. Before culture, DOs and COCs were washed with D-PBS and finally with culture medium.

\section{Maturation culture}

The maturation medium was TCM-199 (Gibco) supplemented with $10 \%(\mathrm{v} / \mathrm{v})$ fetal calf serum (FCS, Gibco), $1 \mu \mathrm{g} / \mathrm{ml} 17 \beta-$ estradiol, $24.2 \mathrm{mg} / \mathrm{l}$ sodium pyruvate, $0.05 \mathrm{IU} / \mathrm{ml}$ folliclestimulating hormone, $0.05 \mathrm{IU} / \mathrm{ml}$ luteinizing hormone and $10 \mathrm{ng} / \mathrm{ml}$ epidermal growth factor. Depending on the experiment, different concentrations of cysteamine or cystine were added to the maturation medium. Cysteamine and cystine stocks were prepared in advance at concentrations of $20 \mathrm{mM}$ and $100 \mathrm{mM}$ respectively and diluted to the desired concentrations before use. Groups of 20-30 oocytes were transferred into a 100- $\mu$ l culture medium under mineral oil. The COCs and DOs were cultured in IVM medium at $38.5^{\circ} \mathrm{C}$ in $5 \% \mathrm{CO}_{2}$ in humidified air for $24 \mathrm{~h}$.

\section{Co-culture of DOs with cumulus cell monolayer}

The COCs obtained from ovaries were pipetted in maturation medium with a narrow-bore pipette to release cumulus cells. After the oocytes were removed, cumulus cells were collected and vigorously pipetted to allow separation of the cells. Then, the cells were counted in a hemocytometer chamber, and aliquots of the cell suspension $\left(100 \mu \mathrm{l}, 3 \times 10^{5}\right.$ cells $/ \mathrm{ml}$ in maturation medium) were placed in the wells of a 96 -well culture plate under mineral oil and cultured at $38.5^{\circ} \mathrm{C}$ in a humidified atmosphere of $5 \% \mathrm{CO}_{2}$ in air. The medium was renewed every $48 \mathrm{~h}$ until $>80 \%$ confluence, which was normally attained within 4-5 days. A RIA of progesterone confirmed that the cumulus cells were not luteinized after 5 days of culture in the oocyte maturation medium. When cumulus cells grew to $80 \%$ of confluence, the spent medium in the wells was replaced with $100 \mu \mathrm{l}$ fresh maturation medium. After a $3 \mathrm{~h}$ of equilibration in a $\mathrm{CO}_{2}$ incubator, DOs were placed in wells (20-30 DOs per well) and cultured for $24 \mathrm{~h}$ at $38.5^{\circ} \mathrm{C}$ in a humidified atmosphere of $5 \% \mathrm{CO}_{2}$ in humidified air.

\section{Chemical activation}

At $24 \mathrm{~h}$ of maturation culture, COCs were stripped of their cumulus cells by pipetting with a thin pipette in D-PBS containing $0.1 \%$ hyaluronidase, and those with an intact first polar body were selected for chemical activation. The DOs with a first polar body were also selected. Oocytes selected were first exposed to $5 \mu \mathrm{M}$ ionomycin for $2 \mathrm{~min}$ at room temperature, and then incubated at $38.5{ }^{\circ} \mathrm{C}$ under $5 \% \mathrm{CO}_{2}$ in humidified air for $3 \mathrm{~h}$ in CR1aa containing $2 \mathrm{mM}$ 6-dimethylaminopurine (6-DMAP) followed by culture for $3 \mathrm{~h}$ in CR1 aa without 6-DMAP. The ionomycin and 6-DMAP stocks were prepared in dimethyl sulfoxide at concentrations of $500 \mu \mathrm{M}$ and $400 \mathrm{mM}$ respectively and diluted to the desired concentrations in CR1 aa supplemented with 5\% FCS before use.

\section{Embryo culture}

Cumulus cells were recovered from in vitro matured goat COCs and cultured in DMEM/F12 supplemented with 10\% FCS in the wells of a 96-well culture plate. The DMEM/F12 in wells with growing monolayer were replaced with CR1aa containing 
$3 \mathrm{mg} / \mathrm{ml} \mathrm{BSA}$ and 5\% FCS and equilibrated for $12 \mathrm{~h}$ prior to embryo culture. After activation treatments, oocytes were placed in the wells (15-20 oocytes per well) with CR1aa and cumulus cell monolayer and cultured for 9 days at $38.5{ }^{\circ} \mathrm{C}$ under $5 \% \mathrm{CO}_{2}$ in humidified air. At the end of culture, embryo development was examined under a phase contrast microscope. Some of the blastocysts were mounted on a slide, stained with Hoechst 33342 and observed for cell counts under a fluorescent microscope.

\section{Assay of GSH}

Intracellular content of GSH was measured as described by Funahashi et al. (1994). Each sample consisted of 30 oocytes and three samples were assayed for each treatment. Oocytes were denuded of cumulus cells (if any) and washed three times in $\mathrm{Ca}^{2+}-, \mathrm{Mg}^{2+}$-free PBS. Five microliters of distilled water containing 30 oocytes was transferred to a $1.5 \mathrm{ml}$ microfuge tube, and then $5 \mu \mathrm{l}$ of $1.25 \mathrm{M}$ phosphoric acid was added to the tube. Samples were frozen at $-70{ }^{\circ} \mathrm{C}$ and thawed at room temperature. This procedure was repeated three times. Then the samples were stored at $-20{ }^{\circ} \mathrm{C}$ until analyzed. Concentrations of GSH in the oocyte were determined by the $5,5^{\prime}$ dithio-bis (2-nitrobenzoic acid)-glutathione disulfide (DTNB-GSSG) reductase-recycling assay. Briefly, $700 \mu \mathrm{l}$ of $0.33 \mathrm{mg} / \mathrm{ml} \mathrm{NADPH}$ in $0.2 \mathrm{M}$ sodium phosphate buffer containing $10 \mathrm{mM}$ EDTA (stock buffer, pH 7.2), $100 \mu \mathrm{l}$ of $6 \mathrm{mM}$ DTNB in the stock buffer, and $190 \mu \mathrm{l}$ distilled water were added and mixed in a microfuge tube. Ten microliters of $250 \mathrm{IU} / \mathrm{ml} \mathrm{GSH}$ reductase were added with mixing to initiate the reaction. The absorbance was monitored continuously at $412 \mathrm{~nm}$ with a spectrophotometer for $3 \mathrm{~min}$, with reading recorded every $0.5 \mathrm{~min}$. Standards $(0.01,0.02,0.1,0.2$, and $1.0 \mathrm{mM}$ ) of $\mathrm{GSH}$ and a sample blank lacking GSH were also assayed. The amount of GSH in each sample was divided by the number of oocytes to get the intracellular GSH concentration per oocyte.

\section{Data analysis}

To observe oocyte maturation and embryo development, each treatment was repeated six times and 20-30 and 15-20 oocytes were observed for maturation and embryo development, respectively, per replicate per treatment. For an assay of intracellular GSH level, each sample contained 30 oocytes and three samples were assayed for each treatment. Percentage data were arc sine transformed and analyzed with ANOVA; a Duncan multiple comparison test was used to locate differences. The software used was Statistics Package for Social Science (SPSS Inc., Chicago, IL, USA). Data are expressed as mean \pm S.E.M. and $P<0.05$ was considered significant.

\section{Acknowledgements}

This study was supported by grants from the Momentous Research Project of the China Ministry of Science and Technology (No. 2007CB947403 and No. 2006CB944003) and from the China National Natural Science Foundation (Nos. 30571337,30771556 and 30430530). The authors declare that there is no conflict of interest that would prejudice the impartiality of this scientific work.

\section{References}

Abeydeera LR, Wang W-H, Cantley TC, Rieke A \& Day BN 1998 Coculture with follicular shell pieces can enhance the developmental competence of pig oocytes after in vitro fertilization: relevance to intracellular glutathione. Biology of Reproduction 58 213-218.

Arrigo AP 1999 Gene expression and the thiol redox state. Free Radical Biology \& Medicine 27 936-944.

Bannai S 1984 Transport of cystine and cysteine in mammalian cells. Biochimica et Biophysica Acta 779 289-306.

Chance B, Sies H \& Boveris A 1979 Hydroperoxide metabolism in mammalian organs. Physiological Reviews 59 527-605.

Chian RC, Niwa K \& Sirard MA 1994 Effects of cumulus cells on male pronuclear formation and subsequent early development of bovine oocytes in vitro. Theriogenology 41 1499-1508.

Funahashi H, Cantley TC, Stumpf TT, Terlouw SL \& Day B 1994 Use of lowsalt culture medium with elevated oocyte glutathione levels and enhanced male pronuclear formation after in vitro fertilization. Biology of Reproduction 51 633-639.

Furnus CC, de Matos DG \& Moses DF 1998 Cumulus expansions during in vitro maturation of bovine oocytes: relationship level and its role on subsequent embryo development. Molecular Reproduction and Development $\mathbf{5 1}$ 76-83.

Gasparrini B, Neglia G, Palo RD, Campanile G \& Zicarelli L 2000 Effect of cysteamine during in vitro maturation on buffalo embryo development. Theriogenology 54 1537-1542.

Gasparrini B, Boccia L, Marchandise J, Palo RD, George F, Donnay I \& Zicarelli L 2006 Enrichment of in vitro maturation medium for buffalo (Bubalus bubalis) oocytes with thiol compounds: effects of cystine on glutathione synthesis and embryo development. Theriogenology 65 275-287.

Ge L, Han D, Lan GC, Zhou P, Liu Y, Zhang X, Sui HS \& Tan JH 2008 Factors affecting the in vitro action of cumulus cells on the maturing mouse oocytes. Molecular Reproduction and Development 75 136-142.

Hashimoto S, Saeki K, Nagao Y, Minami N, Yamada M \& Utsumi K 1998 Effects of cumulus cell density during in vitro maturation of the developmental competence of bovine oocytes. Theriogenology 49 1451-1463.

Issels RD, Nagele A, Eckert KG \& Wilmanns W 1988 Promotion of cystine uptake and its utilization for glutathione biosynthesis induced by cysteamine and N-acetylcysteine. Biochemical Pharmacology 37 881-888.

Kobayashi M, Lee ES \& Fukui Y 2006 Cysteamine or beta-mercaptoethanol added to a defined maturation medium improves blastocyst formation of porcine oocytes after intracytoplasmic sperm injection. Theriogenology 65 1191-1199.

Lan GC, Chang ZL, Luo MJ, Jiang YL, Han D, Wu YG, Han ZB, Ma SF \& Tan JH 2006 Production of cloned goats by nuclear transfer of cumulus cells and long-term cultured fetal fibroblast cells into abattoir-derived oocytes. Molecular Reproduction and Development 73 834-840.

Luciano AM, Lodde V, Beretta MS, Colleoni S, Lauria A \& Modina S 2005 Developmental capability of denuded bovine oocyte in co-culture system with intact cumulus-oocyte complexes: role of cumulus cells, cyclic adenosine $3^{\prime}, 5^{\prime}$-monophosphate, and glutathione. Molecular Reproduction and Development 71 389-397.

Maedomari N, Kikuchi K, Ozawa M, Noguchi J, Kaneko H, Ohnuma K, Nakai M, Shino M, Nagai T \& Kashiwazaki N 2007 Cytoplasmic glutathione regulated by cumulus cells during porcine oocyte maturation affects fertilization and embryonic development in vitro. Theriogenology 67 983-993.

de Matos DG \& Furnus CC 2000 The importance of having high glutathione level after bovine in vitro maturation on embryo development: effect of b-mercaptoethanol, cysteine, and cystine. Theriogenology 53 761-771.

de Matos DG, Furnus CC, Moses DF \& Baldassarre H 1995 Effect of cysteamine on glutathione level and developmental capacity of bovine oocyte matured in vitro. Molecular Reproduction and Development 42 432-436.

de Matos DG, Furnus CC, Moses DF, Martinez AG \& Matkovic M 1996 Stimulation of glutathione synthesis of in vitro matured bovine oocytes and its effect on embryo development and freezability. Molecular Reproduction and Development 45 451-457. 
de Matos DG, Furnus CC \& Moses DF 1997 Glutathione synthesis during in vitro maturation of bovine oocytes: role of cumulus cells. Biology of Reproduction 57 1420-1425.

de Matos DG, Gasparrini B, Pasqualini SR \& Thompson JG 2002 Effect of glutathione synthesis stimulation during in vitro maturation of ovine oocytes on embryo development and intracellular peroxide content. Theriogenology 57 1443-1451.

de Matos DG, Nogueira D, Cortvrind R, Herrea C, Adriaenssens T, Pasqualini RS et al. 2003 Capacity of adult and prepubertal mouse oocytes to undergo embryo development in the presence of cysteamine. Molecular Reproduction and Development 64 214-218.

Meier T \& Issels R 1995 Promotion of cyst(e)ine uptake. Methods in Enzymology 252 103-112.

Meister A 1983 Selective modification of glutathione metabolism. Science $220472-477$.

Meister A \& Tate SS 1976 Glutathione and the related y-glutamyl compounds: biosynthesis and utilization. Annual Review of Biochemistry 45 559-604.

Michaelis L \& Menten ML 1913 Die Kinetik der Invertinwerkung. Biochemische Zeitschrift 49333.

Perreault SD, Barbee RR \& Slott VL 1988 Importance of glutathione in the acquisition and maintenance of sperm nuclear decondensing activity in maturing hamster oocytes. Developmental Biology 125 181-186.

Rodriguez-Gonzalez E, Lopez-Bejar M, Mertens MJ \& Paramio MT 2003 Effects on in vitro embryo development and intracellular glutathione content of the presence of thiol compounds during maturation of prepubertal goat oocytes. Molecular Reproduction and Development 65 446-453.

Sagara J, Miura K \& Bannai S 1993 Cystine uptake and glutathione level in fetal brain cells in primary culture and in suspension. Journal of Neurochemistry 61 1667-1671.

Sawai K, Funahashi H \& Niwa K 1997 Stage-specific requirement of cysteine during in vitro maturation of porcine oocytes for glutathione synthesis associated with male pronuclear formation. Biology of Reproduction 57 1-6.
Schroeder AC \& Eppig JJ 1984 The developmental capacity of mouse oocytes that matured spontaneously in vitro is normal. Developmental Biology 102 493-497.

Sutovsky P \& Schatten G 1997 Depletion of glutathione during bovine oocyte maturation reversibly blocks the decondensation of the male pronucleus and pronuclear apposition during fertilization. Biology of Reproduction 56 1503-1512.

Takahashi M, Nagai T, Okamura N \& Okano A 1995 Effect of co-culture cells on the uptake of cystine into bovine embryos. Theriogenology 43 332.

Tanghe S, Van Soom A, Nauwynck H, Coryn M \& de Kruif A 2002 Minireview: functions of the cumulus oophorus during oocyte maturation, ovulation, and fertilization. Molecular Reproduction and Development 61 414-424.

Wongsrikeao P, Kaneshige Y, Ooki R, Taniguchi M, Agung B, Nii M \& Otoi T 2005 Effect of the removal of cumulus cells on the nuclear maturation, fertilization and development of porcine oocytes. Reproduction in Domestic Animals 40 166-170.

Yamauchi N \& Nagai T 1999 Male pronuclear formation in denuded porcine oocytes after in vitro maturation in the presence of cysteamine. Biology of Reproduction 61 828-833.

Yoshida M, Ishigaki K, Nagai T, Chikyu M \& Pursel VG 1993 Glutathione concentration during maturation and after fertilization in pig oocytes: relevance to the ability of oocytes to form male pronucleus. Biology of Reproduction 49 89-94.

Zhang L, Jiang S, Wozniak PJ, Yang X \& Godke RA 1995 Cumulus cell function during bovine oocyte maturation, fertilization, and embryo development in vitro. Molecular Reproduction and Development $\mathbf{4 0}$ 338-444.

Received 1 January 2008

First decision 23 January 2008

Accepted 23 January 2008 